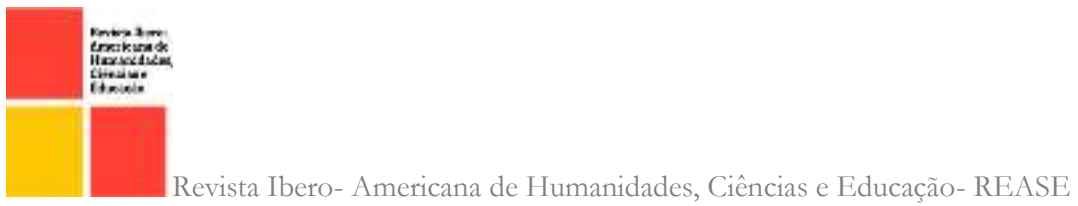

\title{
FILMES, CONVERSAÇÕES E AFETOS NO CURRÍCULO ESCOLAR DA MENINA NEGRA
}

\author{
MOVIES, CONVERSATIONS AND AFFECTIONS IN THE BLACK GIRL'S \\ SCHOOL CURRICULUM
}

\section{Daniela Rebello Pereira Sylvestre ${ }^{1}$}

RESUMO: As imagens possuem o poder de construir e transmitir discursos, modelando opiniões públicas e comportamentos sociais, fornecendo o material com o qual as pessoas constroem suas identidades. Atualmente, o principal fundamento da configuração do mundo é a indissociabilidade entre política e representação, cuja relação intensifica-se pela força da ubiquidade da tecnologia. Vive-se na sociedade do espetáculo à mercê da indústria cultural. Sendo assim, este artigo buscará investigar as relações de gênero, remetendo-as ao caráter social e histórico, bem como a interface dessas categorias com as questões raciais, no contexto educacional e das práticas pedagógicas específicas e diferenciadas que contemplem a história, cultura e conhecimentos do negro para o fortalecimento da identidade da menina negra. $O$ filme é compreendido como a arte que, promovendo a experiência estética, possibilita olhar criticamente determinadas realidades. Assim, se propõe um currículo com a potência das comunidades de afeto e conversações com análise crítica dos filmes infanto-juvenis brasileiros para a formação da identidade étnico-racial da menina negra. Este artigo buscará uma complementaridade entre os seguintes pensadores e as teorias em que se pautam, como a Pedagogia histórico-crítica (Dermeval Saviani), Teoria da prática libertadora (bell hooks) e da potência da comunidade de afetos (Janete Magalhães Carvalho).

Palavras-chave: Filmes infanto-juvenis. Identidade étnico-racial. Educação Antirracista. Currículo escolar.

ABSTRACT: Images have the power to construct and transmit discourses, modeling public opinions and social behavior, providing the material with which people build their identities. Currently, the main foundation of the configuration of the world is the inseparability between politics and representation, whose relationship is intensified by the strength of the ubiquity of technology. We live in the society of the spectacle at the mercy of the cultural industry. Therefore, this article will seek to investigate gender relations, referring them to the social and historical character, as well as the interface of these categories with racial issues, in

\footnotetext{
${ }^{\mathrm{I}}$ Professora de Língua Portuguesa, servidora pública do RJ e do município de Magé. Pós-graduada em Leitura e Produção Textual e Neuropsicopedagogia. ID Orcid:oooo-0oo3-0521-3024.; E-mail: drebellop@gmail.com.
} 


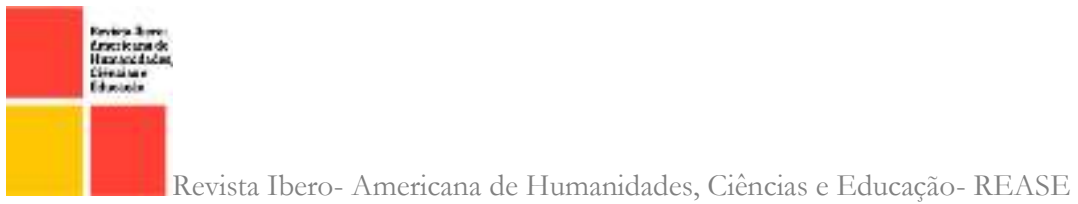

the educational context and specific and differentiated pedagogical practices that include history, culture and knowledge of the black to strengthen the identity of the black girl. Film is understood as the art that, promoting the aesthetic experience, makes it possible to critically look at certain realities. Thus, a curriculum with the power of communities of affection and conversations with critical analysis of Brazilian children's films is proposed for the formation of the ethnic-racial identity of the black girl. This article will seek a complementarity between the following thinkers and the theories on which they are based, such as Historical-Critical Pedagogy (Dermeval Saviani), Theory of Liberating Practice (bell hooks) and the potency of the community of affections (Janete Magalhães Carvalho).

Keywords: Children's films. Ethnic-racial identity. Anti-racist education. School curriculum.

\section{I- INTRODUÇÃO}

Com o objetivo de reconhecer e difundir a cultura africana, tão presente na constituição do patrimônio, identidade e cultura brasileira, a Lei 10.639/o3 tornou obrigatório o ensino de História e Cultura Afro-brasileira e Africana nas escolas de todo o país, resgatando a contribuição do povo negro nas áreas social, econômica e política pertinentes à História do Brasil. A Lei II.645/2008 alterou a Lei 9.394/1996, modificada pela Lei $10.639 / 2003$, a qual estabelece as diretrizes e bases da educação nacional, para incluir no currículo oficial da rede de ensino a obrigatoriedade da temática "História e cultura afro-brasileira e indígena". Sabe-se que o racismo no Brasil é estrutural (histórico, social e cultural), por isso a importância dessa lei, entretanto, a mesma ainda não é aplicada tal como deveria ser.

Desde o século passado, na década de 1960, Guy Debord já afirmava que o poder espetacular está disseminado por toda a vida social, na qual há simultaneamente produção e consumo de mercadorias e de imagens, ou ocorre vinculado à ação do Estado, de forma concentrada, com a produção de imagens para justificar o poder exercido por seus dirigentes.

Observando e analisando as mídias audiovisuais, em especial os filmes infanto-juvenis, atualmente, constatam-se que as personagens são em sua maioria brancos, há raras exceções de protagonismo de meninas negras. 


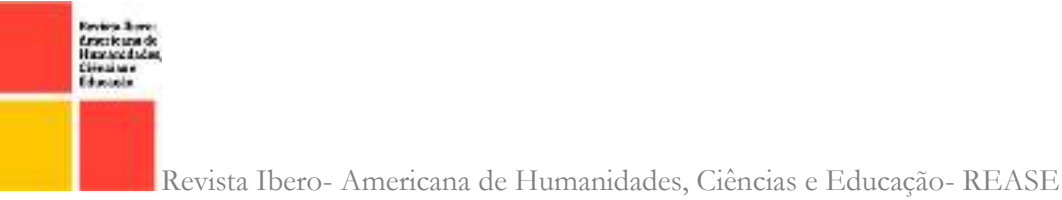

Há estudos científicos que comprovam que viver o racismo, direta ou indiretamente, tem efeitos de longo prazo sobre desenvolvimento, comportamento, saúde física e mental. De acordo com um estudo publicado no principal periódico da Associação Americana de Psicologia, as crianças aos seis anos são capazes de entender que há uma hierarquia racial como podem elas mesmas se engajarem em estereótipos racistas diretos.

Apesar das pesquisas que demonstram as consequências de os estresses da discriminação serem estadunidenses, é possível fazer um paralelo com nosso país, pelo fato de termos histórico de escravidão e desigualdades. A exposição constante ao racismo, é acentuado ainda mais na infância com os filmes infanto-juvenis.

A conclusão desses estudos do Centro de Desenvolvimento Infantil da Universidade de Harvard e da Sociedade Americana de Psicologia é a de que ser alvo de racismo estrutural de suas formas mais sutis às mais escandalizadas têm um efeito às vezes "invisível", mas duradouro e cruel sobre a saúde, o corpo e o cérebro de crianças. Esses impactos na saúde física e mental dos negros, nas meninas é ainda maior, devido além da discriminação racial estar associada ao sexismo.

A longo prazo, isso resulta em custos bilionários adicionais em saúde, na perpetuação das disparidades raciais e em mais dificuldades para grande parcela da população em atingir seu pleno potencial humano e capacidade produtiva.

De acordo com a lei 9.394/1996 (LDB), há obrigatoriedade pela Constituição (art. 208) a determinação, em seu art. 60 de que é dever dos pais ou responsáveis efetuar a matrícula das crianças na educação básica a partir dos quatro anos de idade, ou seja, desde muito pequena, a criança está no ambiente escolar, em contato com professores, que podem ter práticas promotoras de igualdade racial e construir uma educação antirracista.

Por isso, o artigo instiga os educadores a pensarem sobre às seguintes questões: As produções cinematográficas infanto-juvenis, mais recentes, apresentaram personagens meninas negras? Como é a construção e a atuação das personagens meninas negras nestas representações audiovisuais? De que maneira o professor pode construir um currículo alicerçado em práticas promotoras de 


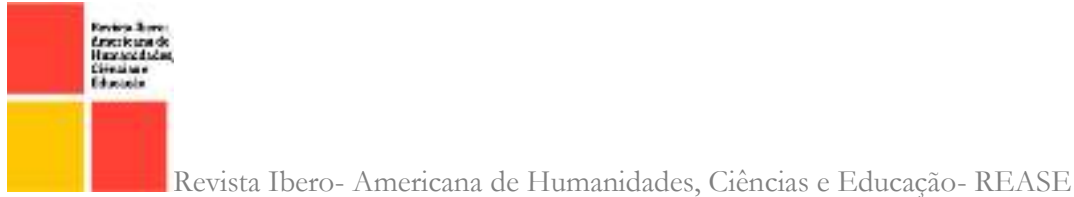

\section{open 8 access}

equidade racial? Para que devemos conscientizar as meninas negras sobre sua função social para serem sujeitos críticos e autônomos?

Nosso objetivo não é o de responder a essas perguntas, mas instigar a reflexão sobre essas questões tão necessárias para a construção da identidade étnicoracial das meninas negras brasileiras.

\section{DESENVOLVIMENTO}

Pautamos essa reflexão nos aspectos epistemológicos gerais do Materialismo histórico dialético, método desenvolvido por Marx e Engels. $\mathrm{O}$ método é assim denominado porque baseia-se no pressuposto de que são as condições materiais que produzem as ideias; essas condições materiais precisam ser compreendidas dentro de sua historicidade, dentro de práticas sociais construídas pelo homem e, por serem produzidas por este, contêm forças antagônicas que são mutáveis pelos homens, consequentemente, dialéticas. O conceito de dialética, já existente antes de Marx, é por ele invertido com o conceito de transformação revolucionária das práticas sociais. Para Marx tudo pode ser transformado pela ação do homem.

Esses pressupostos teóricos do Materialismo histórico dialético fornecem fundamentos aos estudiosos nos quais embasamos este estudo: a Pedagogia históricocrítica (Dermeval Saviani), Teoria da prática libertadora (bell hooks) e da potência da comunidade de afetos (Janete Magalhães Carvalho).

Na segunda metade do século XIX, iniciou-se o processo de Revolução gráfica que inundou de ilustrações as publicações até então, dominadas pelo texto. A sociedade do espetáculo corresponde a uma fase específica da sociedade capitalista, quando há uma interdependência entre o processo de acúmulo de capital e o processo de acúmulo de imagens. O papel desempenhado pelo marketing, sua onipresença, ilustra perfeitamente bem o que Guy Debord quis dizer: das relações interpessoais à política, passando pelas manifestações religiosas, tudo está mercantilizado e envolvido por imagens.

$\mathrm{Na}$ sociedade de classes, o espetáculo cumpre uma função equivalente a que cumpria a religião nas sociedades tradicionais ou a arte na formação do capitalismo. 
Tendo como lógica fazer da representação, que mostra algo mais real que a experiência vivida, algo mais real do que nossas próprias necessidades, reduzindo o indivíduo à condição de espectador passivo na política, na produção e no consumo, na aceitação do estado de coisas existente.

A indústria cultural seduz o público com espetáculo e leva-o a identificar-se com certas opiniões, sentimentos e comportamentos, ajustados aos valores, às instituições, às crenças e às práticas vigentes. $O$ espetáculo é descrito pelo autor como um dos princípios organizacionais da economia, da política, da sociedade e da vida cotidiana.

A atualidade das concepções marxistas é potente em crítica ao capitalismo e ajuda-nos a compreender os movimentos culturais contemporâneos como o protagonismo feminino e o antirracismo, pois ambos são consequências de tensões internas no capitalismo neoliberal vigente.

\section{2.r. Pedagogia histórico-crítica}

A pedagogia histórico-crítica, segundo Saviani, "está empenhada em elaborar as condições de organização e desenvolvimento da prática educativa escolar como um instrumento potencializador da luta da classe trabalhadora pela transformação estrutural da sociedade atual." (SAVIANI, 2019:19)

Esta pedagogia também tem seus pressupostos teóricos alicerçados no Materialismo histórico dialético, por isso, o currículo, nessa teoria, compreende que a formação da consciência é reflexo da realidade e se preocupa com os elementos naturais e culturais necessários à constituição da humanidade em cada ser humano $e$ à descoberta de formas adequadas para atingir esse objetivo. Ele é de construção coletiva e situa-se na categoria de trabalho não-material, que ele define como sendo a produção de saber, seja do saber sobre a natureza, sobre a cultura, isto é, o conjunto da produção humana. No currículo cabem os conteúdos prioritariamente fundamentais para o desenvolvimento humano na formação omnilateral, ou seja, a seleção de quais conteúdos produzidos historicamente devem ser incluídos para que seja instrumento para a emancipação do humano. 

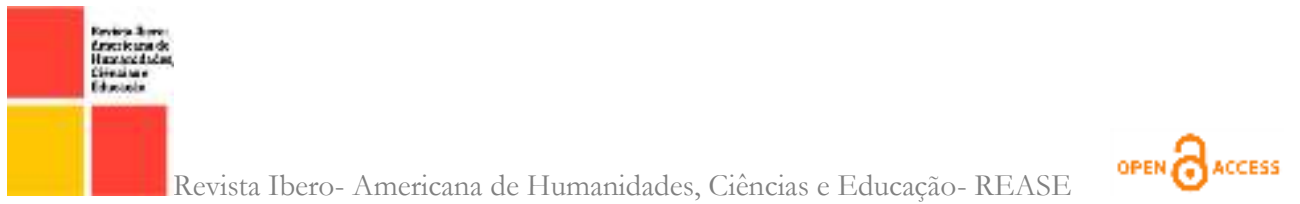

Para Saviani é função social da escola proporcionar os meios para o acesso ao conteúdo clássico, mas que não deve ser confundido com o tradicional e também que aquele não se opõe ao atual. É a partir do conhecimento e saber sistematizado que o currículo escolar deve ser estruturado.

Compreendida por ele como ciência da educação, essa pedagogia tem uma diretriz que envolve dois aspectos. Em primeiro lugar a pesquisa partindo de produções anteriores submetidas à crítica destes pressupostos, assim como dos próprios achados e em segundo lugar a investigação desinteressada a verdade.

Os conglomerados empresariais são fundamentais para a existência da sociedade capitalista, e produzem a indústria cultural. Dentro desta, ocorre o que Debord conceituou como a sociedade do espetáculo. O espetáculo é o conjunto das relações sociais mediadas pelas imagens, é impossível a separação entre essas relações sociais, as relações de produção e consumo de mercadorias. $\mathrm{Na}$ sociedade do espetáculo, a onipresença do marketing, demonstra como tudo está mercantilizado, envolvido por imagens e a maioria dos espectadores é passiva diante desses recortes escolhidos para serem apresentados.

É por isso que é de suma relevância discutir e pesquisar sobre o poder da imagem sobre as meninas afro-brasileiras, um grupo historicamente discriminado e já traumatizado pela experiência colonial. O olhar branco hegemônico e suas objetificações, ainda é profundamente arraigado nos filmes infanto-juvenis.

\subsection{Práticas promotoras de equidade racial}

Considerando a nova configuração do mundo, que tem como indissociabilidade entre política e representação, a pesquisadora bell hooks dedicase a empreender uma crítica dos produtos e dispositivos da indústria cultural (filmes, livros, programas televisivos, ícones da cultura pop) que circulam em nossa época, nas trocas comunicativas que se intensificam por força da ubiquidade da tecnologia.

A autora tem uma variedade de reflexões acerca do que significou e significa o processo de colonização e de dominação nos países marcados pela escravidão 

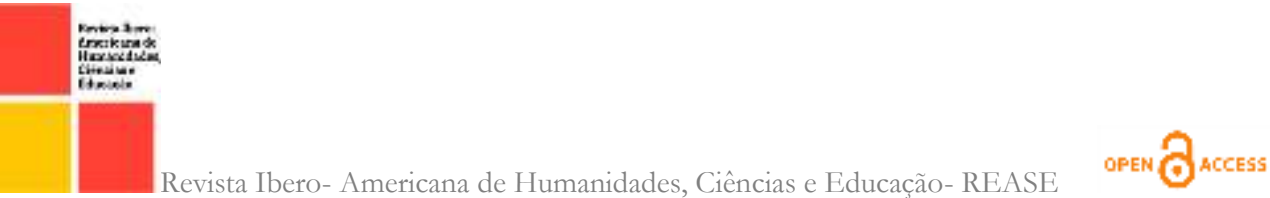

transatlântica. Além disto, a autora é uma pensadora feminista revolucionária e oferece ferramentas teóricas e práticas para reescrever a história dos dominados, buscando educar uma consciência crítica, ensinando as pessoas a agirem contra hegemonicamente. Ela luta não só por igualdade entre os gêneros no mercado de trabalho, mas pelo fim do patriarcado, pela reforma e reestruturação geral da sociedade, pelo fim do sexismo e do racismo.

Entretanto, hooks afirma que antes que as mulheres possam mudar o patriarcado, faz-se necessário que mudem a si mesmas, que criem consciência. A conscientização feminista revolucionária enfatizou a importância de aprender sobre o patriarcado como sistema de dominação, como ele se institucionaliza e como é disseminado e mantido. Compreender a maneira como a dominação masculina e o sexismo são expressos no dia a dia conscientiza mulheres sobre como são vitimizadas, exploradas e, em piores cenários, oprimidas. (HOOKS, 2018: 23)

Além de hooks, outra importante pesquisadora sobre as questões de negritude e feminismo, é a brasileira Lélia Gonzales. Ela tem inegável pioneirismo na crítica ao racismo estrutural na sociedade brasileira e na articulação entre racismo e sexismo, propondo o conceito de feminismo afro-latino-americano, reconheceu que ser negra e mulher no Brasil, é ser objeto de tripla discriminação, uma vez que os estereótipos gerados pelo racismo e pelo sexismo a colocam no mais alto nível de opressão. Em seus estudos e textos, ela demonstrou que muitas discussões feministas apesar de tratarem das relações de dominação sexual, social e econômica a que a mulher está submetida, não atentam para o fato da opressão racial. A autora percebeu que era impossível combater o racismo se as pessoas brancas não reconhecessem a condição colonial do negro. Uma tarefa difícil, visto que estigmatizar e denegrir o negro faz parte da dominação cultural, dominar, sobretudo, o imaginário do povo dominado é estratégico.

Gonzales afirmou em diversas reportagens sobre o seu despertar e processo de "tornar-se negra", que foi após muito estudo e quando já era adulta. Este fato, torna-se mais um argumento pontual, a medida em que assim como ela, no século passado, muitas meninas, na pós-modernidade, ainda são subjugadas e "forçadas" a 
um embranquecimento, onde as mídias audiovisuais têm um papel preponderante para isso.

\subsection{Redes de conversações e comunidades de afetos}

Defendemos a ideia de currículo escolar como redes de conversações e ações complexas, apresentada por Carvalho, que mesmo focando no cotidiano escolar, compreende-o como parte integrante de um trabalho social que direta e indiretamente se enreda com os processos de produção de subjetividades na sociedade capitalista.

Para a autora, o currículo como comunidade de afetos e afecções tem o potencial de ação coletiva, que depende fundamentalmente da "capacidade de indivíduos e grupos colocarem-se em relação para produzirem e trocarem conhecimentos, produzindo, então, o agenciamento de formas/forças comunitárias, com vistas a melhorar os processos de aprendizagem" (CARAVALHO, 20II: 75)

Dessa forma, propõe-se práticas pedagógicas que incluam os filmes infantojuvenis brasileiros no currículo escolar, pois não podemos desvencilhar a vida cotidiana da vida escolar. Como seres sociais que somos, essas esferas se imbricam. A criança, particularmente a menina negra brasileira tem acesso aos filmes, devido as vastas possibilidades que as tecnologias digitais proporcionam. Por isso, é preciso conversar sobre essas produções, mesmo que não tenham personagens negras, que se debatam sobre os motivos para essa invisibilidade, sobre os sentimentos delas ao assistirem ao filme e sobre o que mais quiserem conversar sobre a negritude na sociedade, para que se identifiquem e analisem criticamente de quais formas essas meninas podem ser afetadas pelas imagens cinematográficas e como o professor valendo-se das imagens cinematográficas pode impulsionar e mobilizar invenções curriculares.

Assim, conforme Carvalho, partiremos:

O pressuposto de que a constituição de currículos compartilhados pode estar na origem de uma nova racionalidade, assim como do desejo de que essa constituição possa avançar à medida que pela linguagem, pelo conhecimento, pelos afetos e afecções se introduzam experimentações e 
exercícios de solidariedade cada vez mais vastos. (CARAVALHO, 20II: 76)

\section{CONCLUSÃO}

As imagens possuem o poder de construir e transmitir discursos, modelando opiniões públicas e comportamentos sociais, fornecendo o material com o qual as pessoas constroem suas identidades.

Segundo bell hooks, quando os feministas deixaram de ser críticos e atentos, o sexismo voltou a aparecer. A literatura infantil é um dos locais cruciais para a educação feminista, para a conscientização crítica, exatamente porque crenças e identidades ainda estão sendo formadas. E, com muita frequência, os pensamentos retrógrados sobre gênero continuam sendo a norma nos parquinhos. (HOOKS, 2018).

Ela afirma que a educação pública para crianças precisa ser uma local onde as ativistas feministas possam fazer seu trabalho de criar currículos sem preconceitos, é preciso alcançar além da palavra acadêmica e concordando com essa perspectiva, acreditamos que os filmes infanto-juvenis também são um veículo de comunicação de massa capaz de contribuir para uma educação feminista para a consciência crítica, se o professor for comprometido, engajado e construir um currículo alicerçado em práticas promotoras de equidade racial, compreendendo currículo como prática social, inserido no contexto histórico, político, social e cultural. Assim como, acreditamos na potência das comunidades de afetos nos cotidianos escolares, proposta por Carvalho, que afirma que as imagens cinematográficas podem impulsionar a formação inventiva e invenções curriculares.

Enfim, podemos concluir por verificarmos a invisibilidade das meninas negras nos longas-metragens infanto-juvenis, lançados no Brasil, mais recentemente, afirmamos a necessidade de se iniciar a luta anti-escravocrata e antissegregacionista, nas escolas brasileiras, desde a primeira infância com as meninas negras para o despertar de sua criticidade. Através da Pedagogia históricocrítica, o professor deve construir um currículo que privilegie a conversação, desenvolver práticas onde os filmes infanto-juvenis sejam discutidos e analisados, para que as alunas negras possam através do diálogo, ter voz, para tornarem-se 
indivíduos críticos, desenvolvendo-se cognitivamente e para serem cidadãs que reconhecem seu lugar na sociedade.

\section{REFERÊNCIAS BIBLIOGRÁFICAS}

BRASIL. Lei n 10630, de o9 de janeiro de 2003. Altera a Lei $\mathrm{n}^{\circ}$ 9.394, de 20 de dezembro de 1996, que estabelece as diretrizes e bases da educação nacional, para incluir no currículo oficial da Rede de Ensino. D.O.U. de I0.I.2003 http://www.planalto.gov.br/ccivil_03/leis/2003/1ro.639.htm

CARVALHO, Janete Magalhães. O CURRÍCULO COMO COMUNIDADE DE AfETOS/AFECÇÕES. Revista Teias, [s. l], v. 13, n. 27, p. 75-87, 20II. Disponível em:

https://www.epublicacoes.uerj.br/index.php/revistateias/article/view/24253/17232 Acesso em: 27 fev. 202I.

O cotidiano escolar como comunidade de afetos. Petrópolis, RJ: DP et

Alii, Brasília, DF: CNPq, 2009.

DEBORD, Guy. A sociedade do espetáculo: comentários sobre a sociedade do espetáculo. Rio de Janeiro: Contraponto, 1997 [1967].

GONZALES, Lélia. Por um feminismo afro-latino-americano: ensaios, intervenções e diálogos. Rio de janeiro: Zahar editora, 2020.

HOOKS, Bell. O feminismo é para todo mundo: políticas arrebatadoras. Rio de Janeiro: Rosa dos tempos, 2018.

Retrato das desigualdades de gênero e raça / Instituto de Pesquisa Econômica Aplicada ... [et al.]. - $4^{\underline{a}}$ ed. - Brasília: Ipea, 20Ir. 39 p. : il. Disponível em: https://www.ipea.gov.br/retrato/pdf/revista.pdf . Acesso em 03 fev. 2021. 
S (Estados Unidos). Harvard University (org.). How Racism Can Affect Child Development. 2020. Disponível em: How Racism Can Affect Child Development . Acesso em: o6 out. 2020 .

SAVIANI, Dermeval. Pedagogia histórico-crítica, quadragésimo ano [livro eletrônico] : novas aproximações. Campinas, SP : Autores Associados, 2019. 